\title{
Factors associated with the development of progressive massive fibrosis in British coalminers: a case-control study
}

\author{
W M MACLAREN, J F HURLEY, H P R COLLINS, A J COWIE \\ From the Institute of Occupational Medicine, Edinburgh EH8 9SU, UK
}

\begin{abstract}
Possible associations between the incidence of progressive massive fibrosis (PMF) over periods of average length 11 years during 1963-80 and a range of explanatory variables, both environmental and medical, were examined in a study group of $\mathbf{4 7 7 2}$ miners and ex-miners using casecontrol methods. Cases were members of the study group who developed PMF during the study period; controls were men who remained free of the disease. Cases and controls were matched on cumulative dust exposure to the start of the study period, colliery of employment, and whether or not employment before and during the study period had been at a single colliery only. Of 257 cases of PMF, 142 were matched to four controls each, 39 to three controls, 33 to two controls, and 31 to a single control only. Twelve cases could not be matched. Age and category of simple pneumoconiosis were each found to be associated with the incidence of PMF, confirming the results of many previous studies. Quetelet's index of body mass (a measure of weight, normalised for height) was found to differ considerably between cases and controls, cases tending to be lighter for their height. The difference did not vary significantly between three groups of collieries, defined by coal rank. Regression analysis confirmed the high level of statistical significance of the difference $(p<0.001)$, allowing for the effects of age and prior category of simple pneumoconiosis. Of the environmental factors considered, an index of residence time of dust in the lungs was found to have the most statistically significant association with the incidence of PMF. The crudeness of the measure used, however, together with unreliability in estimates of early exposure to dust for some of the men studied, means that further work is necessary to investigate the magnitude and significance of this apparent association. In low and medium rank collieries there were large differences between the proportion of cases and controls showing a range of respiratory symptoms, cases consistently displaying a higher prevalence. In the high rank collieries of south Wales, however, symptoms occurred with equal frequency in cases and controls, the prevalence at these collieries being the same as among cases generally. Regression analysis (low and medium rank collieries only) showed that the presence of breathlessness was the symptom most strongly associated with the risk of attack of PMF, allowing for the effects of age and Quetelet's index.
\end{abstract}

A recently reported statistical analysis' of data gathered as part of the British National Coal Board's Pneumoconiosis Field Research (PFR) between 1953 and 1980 , and pertaining to more than 30000 British coalminers, confirmed that cumulative exposure to mixed coalmine dust plays a central part in the development of progressive massive fibrosis (PMF). In addition, the age of the men studied, their category of coalworkers' simple pneumoconiosis (CWSP), and

Accepted 26 September 1988 their colliery of employment were all shown to be associated with their risk of developing PMF over five year periods after allowing for the effects of exposure to dust.

This large scale study of working miners involved relatively few explanatory variables. The same limited set of characteristics was considered in subsequent analyses of the incidence of PMF in a subgroup of 4772 men, $^{2}$ following up earlier reports of high crude attack rates in men who had left the industry. ${ }^{3}$ The present paper reconsiders the incidence of PMF in the 
4772 miners and ex-miners to determine what part if any is played by numerous other factors, both environmental and medical, not considered in the previous analyses of these data.

Other workers have reported on possible associations of the incidence of PMF with such diverse factors as tuberculosis infection, ${ }^{4}$ smoking habit, ${ }^{4}$ body type, ${ }^{5}$ job type ${ }^{6}$ and dust composition. ${ }^{7}$ Some of these were examined afresh in this study and the influence of two other aspects of lifetime exposure, the residence time of dust in the lungs and the mean particle size of the dust, was also considered. In addition, lung function level and the presence of a range of respiratory symptoms were considered as factors possibly predisposing to PMF.

\section{Men studied}

The study group comprised 4772 men each of whom had attended the first and third rounds of PFR surveys (in 1953-8 and 1963-8 respectively), ${ }^{8}$ and also the socalled follow up survey of miners and ex-miners in 1974-80. ${ }^{9}$ The main characteristics of this group have already been described. ${ }^{2}$ (Analyses involving respiratory symptoms questionnaire data were carried out on only 4749 of the men because of unreliable or missing data.)

By the time of the follow up survey, approximately $56 \%$ of the men had left the coal industry.

\section{Characteristics of the men studied}

\section{RADIOLOGICAL DATA}

Each man in the study group had a full sized posteroanterior chest radiograph taken at the first, third, and follow up surveys. All follow up survey radiographs were classified for epidemiological purposes using the ILO U/C classification ${ }^{10}$ and the independent randomised method of film reading. Classifications were made independently of one another by five members of a panel of readers (four of whom were not medically qualified), self trained in the use of the ILO classification, and monitored over several years. " Follow up survey films were regarded as showing PMF if a majority of the reading panel recorded the presence of large shadows.

Each third survey film from four of the 24 collieries participating in the third round of PFR surveys was read by two medically qualified readers and a so-called definitive classification of the film was obtained from these readings. ${ }^{12}$ At the remaining 20 collieries, only one reading per film was obtained. PMF was recorded as category A, B, C, or PMF undefined; the classification of simple pneumoconiosis referred to the four major categories, 0 to $3 .^{13}$

\section{CUMULATIVE DUST EXPOSURE}

The numbers of hours worked by each man in thez study group between first and third surveys had been monitored as part of the PFR. Gaps in men's time records caused by either coalmining experience befores the first survey or by periods of work at non-PFRO collieries were filled using occupational history infor mation obtained at interview. Summation of these data gave a measure of time contributing to cumulative dust exposure to third survey. Cumulativen dust exposures up to third PFR survey were calculated? by first breaking down the time contributing to exposure between first and third surveys into periods $\vec{\omega}$ worked within occupational groups. Dust concentra-N tions within these groups had been measured as part of the PFR, and exposures were calculated as sums of products of these concentrations and time. To cover periods in men's working experience where noo measured concentrations were available, estimatesir based on PFR data were made of concentrations within six broad classes of coalmining activity, and these were combined with occupational history infor- $\overrightarrow{-}$ mation obtained at interview. These methods ared described in greater detail elsewhere. ${ }^{1914}$

\section{RESIDENCE TIME}

An approximate index of residence time of dust in the lungs before the third survey was derived for each mgn as follows. Estimates of 2.5, 7.5, and 17.5 years we e taken for the periods during which dust inhaled between surveys 2 and 3 , between surveys 1 and 2 , a anids before survey 1 respectively had resided in the lungs before the third PFR survey. These three figures were averaged using as weights the dust exposures acquired $\frac{D}{2}$ during the corresponding periods. Units of measure $-\vec{A}$ ment are in years and the index is constrained to be between $2 \cdot 5$ and $17 \cdot 5$.

CUMULATIVE QUARTZ EXPOSURE, KAOLIN PLUS MICA EXPOSURE, AND ASSOCIATED MEASURES Measurements of dust composition, other than microscopical counts of non-coal particles, were not 3 made routinely between the first and third PFR surveys. Subsequently, however, dust samples obtained between surveys one and three were bulked and analysed ${ }^{15}$ to give values of the quartz and kaolin? plus mica content of the respirable dust. The corres $\frac{7}{0}$ ponding concentrations were linked with information on where the men in the study group had worked, and for how long, to provide measures of cumulative exposure up to the third survey. Gaps in exposure were estimated in the same way as those occurring in $\omega$ cumulative dust exposures. Quartz and kaolin plus? mica concentrations were obtained from the corres $\frac{10}{2}$ ponding exposure measures divided by the time contributing to cumulative dust exposure. 
INDEX OF PARTICLE SIZE

Analysis of airborne dust samples obtained between first and third surveys had shown that the frequency distribution of projected diameters of the dust particles greater than one micron could be described by an exponential distribution. ${ }^{16}$ This provided an efficient method of characterising the distribution by a single index. (Note that the index has dimensions (length) ${ }^{-1}$; larger values of the index imply finer dusts.) Values of these indices were available for each occupational group and a mean value for each man in the study was obtained by averaging over periods of work within occupational groups, weighting by dust exposure. Estimates of the index obtained from PFR data were used for those periods of men's work experience for which no measurements were available. The methods used to fill such gaps were analogous to those described above for cumulative dust exposures.

\section{QUESTIONNAIRE DATA: RESPIRATORY SYMPTOMS} AND SMOKING HABITS

A questionnaire on respiratory symptoms and smoking habits was administered by trained personnel at each round of PFR surveys except the first. The questionnaire was first described by Rogan et al and a version of it is given as an appendix to that paper. ${ }^{17}$ The version used at the third survey contains minor differences in the section on smoking and is reproduced by Hurley et al. ${ }^{18}$ Nine dichotomous respiratory symptoms variables were derived from the questionnaire items; they are listed in the lower part of table 1 of the present paper. Briefly, the variables indicate presence or absence of morning or day cough, morning or day phlegm, breathlessness, wheeze, whether or not the weather affects the chest, whether or not there has been a chest illness during the previous three years, and, finally, a variable derived from a combination of certain of the earlier eight, indicating the presence or absence of respiratory symptoms. (The exact definition was as follows: respiratory symptoms were held to be present if the weather affected the chest and wheeze was present. Furthermore, if either of these symptoms, or breathlessness, or a history of recent chest illness was present, and cough or phlegm throughout the day was also present, respiratory symptoms were again taken as present. Otherwise, the derived variable was set to zero, indicating no respiratory symptoms.) Men were classed as smokers if they answered "yes" to the question "Do you smoke?"; as ex-smokers if they no longer smoked, but said that they had smoked, at one time, at least one cigarette a day for a year; and as non-smokers otherwise.

\section{LUNG FUNCTION MEASURES}

At the third survey medical examination, three

tble 1 Mean values of listed characteristics, or percentage showing listed attributes, with associated standard errors of case-control ferences*

\begin{tabular}{|c|c|c|c|c|c|c|}
\hline \multirow[b]{2}{*}{ saracteristic } & \multirow[b]{2}{*}{$\begin{array}{l}\text { Study group } \\
\text { mean (SD) } \\
(4749 \text { men) }\end{array}$} & & \multicolumn{4}{|l|}{ Colliery group } \\
\hline & & & $\begin{array}{l}\text { All collieries } \\
(245 \text { matched sets })\end{array}$ & $\begin{array}{l}\text { Low rank collieries } \\
\text { (122 matched sets) }\end{array}$ & $\begin{array}{l}\text { Medium rank } \\
\text { collieries } \\
\text { ( } 43 \text { matched sets) }\end{array}$ & $\begin{array}{l}\text { High rank } \\
\text { collieries } \\
(80 \text { matched sets })\end{array}$ \\
\hline \multirow{3}{*}{$\begin{array}{l}\text { NSP category } \\
(0,1,2,3)(4772 \text { men }) \\
: V_{1}(1)\end{array}$} & $0.29(0.66)$ & Cases & $1 \cdot 12$ & 1.02 & $1 \cdot 16$ & $1 \cdot 25$ \\
\hline & & Difference (SE) & $0.60(0.07)$ & $0.51(0.09)$ & $0.79(0 \cdot 18)$ & $0.64(0 \cdot 12)$ \\
\hline & $3.00(0 \cdot 78)$ & $\begin{array}{l}\text { Cases } \\
\text { Difference (SE) }\end{array}$ & $\begin{aligned} & 2.62 \\
- & 0.13(0.05)\end{aligned}$ & $\begin{aligned} 2.57 \\
-0.16(0.07)\end{aligned}$ & $\begin{aligned} & 2.68 \\
- & 0.15(0.09)\end{aligned}$ & $\begin{aligned} & 2.67 \\
&-0.08(0.09)\end{aligned}$ \\
\hline \multirow[t]{2}{*}{${ }^{\prime} \mathrm{C}(\mathbf{l})$} & $3.98(0.85)$ & Cases & 3.59 & 3.56 & $3 \cdot 72$ & 3.56 \\
\hline & & Difference (SE) & $-0.15(0.06)$ & $-0.16(0.08)$ & $-0.14(0.11)$ & $-0.14(0.11)$ \\
\hline$\vdots \mathrm{V}_{1} / \mathrm{FVC}(\%)$ & $74.9 \quad(8 \cdot 0)$ & Cases & $72 \cdot 6$ & 71.8 & 71.4 & $74 \cdot 6$ \\
\hline \multirow{2}{*}{ Jrning cough (\%) } & $38 \cdot 6$ & $\begin{array}{l}\text { Difference (SE) } \\
\text { Cases }\end{array}$ & $\begin{array}{r}-0.5 \\
56.3\end{array}$ & $\begin{array}{r}-0.9 \\
59.0\end{array}(0.8)$ & $\begin{array}{r}-1.2 \\
51.2\end{array}(1 \cdot 1)$ & $\begin{array}{r}0.5 \quad(1 \cdot 3) \\
55.0\end{array}$ \\
\hline & & Difference (SE) & $8.9(3.8)$ & $15 \cdot 7(5.2)$ & $13.8 \quad(8.4)$ & $-4 \cdot 2(7 \cdot 1)$ \\
\hline \multirow[t]{2}{*}{$y$ cough $(\%)$} & $21 \cdot 6$ & Cases & $35 \cdot 1$ & $37 \cdot 7$ & 34.9 & $31 \cdot 3$ \\
\hline & & Difference (SE) & $8.9(3.5)$ & $14 \cdot 4 \quad(4 \cdot 7)$ & $20.0(7 \cdot 9)$ & $-5.4(6.5)$ \\
\hline srning phlegm (\%) & $35 \cdot 6$ & $\begin{array}{l}\text { Cases } \\
\text { Difference (SE) }\end{array}$ & $\begin{array}{l}54 \cdot 3 \\
10.7 \quad(3.6)\end{array}$ & $\begin{array}{ll}56.6 & \\
16.7 & (5.2)\end{array}$ & $46 \cdot 5$ & 55.0 \\
\hline \multirow[t]{2}{*}{ y phlegm (\%) } & $21 \cdot 9$ & Cases & $34 \cdot 7(-0)$ & 33.6 & $30.2(1.0)$ & $38.7(0.7)$ \\
\hline & & Difference (SE) & $7 \cdot 4(3.3)$ & $11 \cdot 3 \quad(4 \cdot 7)$ & $13.0(7.4)$ & $-1.5(6.0)$ \\
\hline :athlessness (\%) & $21 \cdot 3$ & $\begin{array}{l}\text { Cases } \\
\text { Difference (SF) }\end{array}$ & 43.3 & 42.6 & $37 \cdot 2$ & $\begin{array}{r}47.5 \\
3.3\end{array}$ \\
\hline \multirow[t]{2}{*}{ leeze (\%) } & $30 \cdot 4$ & $\begin{array}{l}\text { Dinerence (SE) } \\
\text { Cases }\end{array}$ & $\begin{array}{l}13.9 \\
47 \cdot 3\end{array}$ & $\begin{array}{l}20 \cdot 4(4 \cdot 9) \\
42 \cdot 6\end{array}$ & $\begin{array}{l}14 \cdot 9(1.9) \\
44 \cdot 2\end{array}$ & $\begin{array}{r}3.3 \\
56 \cdot 2\end{array}$ \\
\hline & & Difference (SE) & $7 \cdot 3 \quad(3 \cdot 7)$ & $9.9(5.4)$ & $15.0(8.5)$ & $-0.7 \quad(6.6)$ \\
\hline \multirow{2}{*}{$\begin{array}{l}\text { ather affecting chest } \\
\%)\end{array}$} & $28 \cdot 5$ & Cases & $45 \cdot 7$ & $42 \cdot 6$ & $46 \cdot 5$ & 50.0 \\
\hline & $23 \cdot 2$ & $\begin{array}{l}\text { Difference (SE) } \\
\text { Cases }\end{array}$ & $\begin{array}{r}8.1 \\
38.8\end{array}$ & $\begin{array}{r}9.0 \\
41 \cdot 0\end{array}(5.4)$ & $\begin{array}{l}17.5 \quad(8 \cdot 3) \\
34.9\end{array}$ & $\begin{array}{r}1.8 \quad(6 \cdot 7) \\
37.5\end{array}$ \\
\hline \multirow{3}{*}{$\begin{array}{l}\text { itory of recent chest } \\
\text { llness (\%) } \\
\text { spiratory symptoms } \\
\%)\end{array}$} & & Difference (SE) & $11.4(3.6)$ & $15 \cdot 1 \quad(5 \cdot 1)$ & $13.4(7 \cdot 7)$ & $4 \cdot 6 \quad(6 \cdot 5)$ \\
\hline & $29 \cdot 1$ & $\begin{array}{l}\text { Cases } \\
\text { Difference (SE) }\end{array}$ & $\begin{array}{r}48.2 \\
9.2\end{array}$ & $\begin{array}{l}45.9 \\
15.5\end{array}(5.1)$ & $\begin{array}{l}41.9 \\
16 \cdot 3(7 \cdot 1)\end{array}$ & $\begin{array}{l}55.0 \\
-4.3\end{array}$ \\
\hline & & Difference (SE) & $9 \cdot 2(3.5)$ & $15 \cdot 2(2 \cdot 1)$ & & $-4 \cdot 3(6 \cdot 3)$ \\
\hline
\end{tabular}

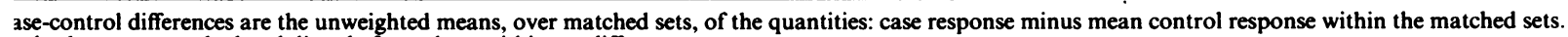
ndard errors are calculated directly from these within-set differences. 
technically satisfactory measurements were taken of forced expiratory volume in one second $\left(\mathrm{FEV}_{1}\right)$ and forced vital capacity (FVC). For purposes of statistical analysis, arithmetic means of the three measures were used, and the ratio of the mean FEV, to mean FVC was also calculated.

QUETELET'S INDEX: A MEASURE OF BODY MASS, ADJUSTED FOR HEIGHT

At each round of the PFR medical examination except the first, standing height (without shoes) and weight were recorded for each man. From the measurements taken at the third survey, Quetelet's index of body mass, defined as weight divided by the square of height, was calculated. ${ }^{19}$

\section{COLLIERY AND PIT PURITY}

At the time of the third PFR survey, the men in the study group were employed at 24 collieries throughout the British coalfield. For the present study, collieries were grouped according to the National Coal Board's coal rank code. ${ }^{20}$ Six south Wales collieries were grouped together as high rank collieries, three collieries in Kent, Lancashire, and the north east respectively as medium rank, and the remaining 15 as low rank collieries.

Men whose entire coalmining experience up to follow up survey was at the research colliery where they were surveyed are referred to as pit pure men.

\section{Epidemiological approach}

\section{STUDY DESIGN}

A case-control approach was used, cases and controls both being selected from the study group of 4772 men. Cases were men whose third survey film was read as showing no PMF and whose follow up survey film was classified by the reading panel as displaying PMF; controls were men whose films from both surveys were classed as free from PMF. Cases and controls were matched on colliery, pit purity status, and cumulative dust exposure to the third PFR survey, the range of exposure being divided into 28 intervals of length $25 \mathrm{gh} / \mathrm{m}^{3}$ for this purpose. It was intended to choose four controls for each case, the selection process being random apart from the constraints imposed by matching. The rationale underlying the matching strategy is outlined in the appendix.

Of the $\mathbf{4 7 7 2}$ men in the study group, 257 developed PMF between the third PFR and follow up surveys. Suitable matched controls were found for 245 of these men: 142 cases were matched to four controls each, 39 to three controls, 33 to two controls, and 31 to a single control only.
STRATEGY OF ANALYSIS

Using measures current at the third PFR survey, cases were compared with controls over a range of factors oB interest. The characteristics investigated were divided. into five groups: prognostic medical variables (res $\stackrel{\vec{f}}{\rightarrow}$ piratory symptoms, CWSP, and lung functiong measures); environmental factors (dust composition particle size, residence time); smoking habit; physique and age and time contributing to exposure, both of which are also correlated with dust exposure. The influence on the incidence of PMF of variables in the last three groups was examined first. These character? istics were of intrinsic interest but also formed a set of $\vec{f}$ variables that were used to adjust estimated effects found in the first two groups. The effects of environo mental factors were studied both in the complete group of 245 cases and 782 controls and in thes subgroup of pit pure men ( 76 cases and 226 controls)

\section{STATISTICAL METHODS}

Two complementary approaches were followed? Firstly, a descriptive analysis of the data was under $\overrightarrow{-}$ taken in which case-control differences were examinedo (relative to estimates of their standard errors) for the्ष various factors taken one at a time. The variation of these differences across colliery groups (defined byd coal rank) was also examined. In parallel with this approach, the magnitude of the effects of various rigk $k_{0}^{\circ}$ factors and their statistical significance were examine ${ }^{0}$ more formally by means of conditional logistic reges sion methods. ${ }^{21}$ Maximum likelihood estimates regression coefficients were obtained using the FORTRAN program RISK. ${ }^{22}$ In the conditionaf logistic regression analysis the statistical significance् of both single variables and groups of variables wastassessed by Wald's test, whereas in stepwise analyseş the criterion for entry into regression equations was based on Rao's score test. ${ }^{23}$ The tables of results show natural exponents of appropriately chosen multiples of regression coefficients. These parameters may bed interpreted as odds ratios or equivalently as approximate relative risks.

\section{Results}

CHARACTERISTICS OF MEN STUDIED

Table 2 shows summary characteristics of the 4772 men studied. An attack of PMF was recorded in 257 men between the third PFR and follow up surveys (arf interval ranging from eight to 15 years), giving a crude attack rate of $5 \cdot 4 \%$. Table 2 shows that the probability of an attack is related to coal rank, category of simplew pneumoconiosis, and pit purity status. Crude attack rates were also related to age at the third survey anc cumulative dust exposure to the third survey. Average ages and exposures for the 257 cases of PMF were 54 
Table 2 Average time at risk and incidences of PMF in selected subsets of the study group

\begin{tabular}{lclr}
\hline & $\begin{array}{l}\text { No } \\
\text { at risk }\end{array}$ & $\begin{array}{l}\text { Time } \\
\text { between } \\
\text { surveys }(y)\end{array}$ & $\begin{array}{l}\text { No (\%) } \\
\text { developing } \\
\text { PMF }\end{array}$ \\
\hline $\begin{array}{l}\text { Low rank collieries } \\
\text { Medium rank collieries }\end{array}$ & 3200 & $11 \cdot 1$ & $127(4 \cdot 0)$ \\
High rank collieries & 509 & $11 \cdot 1$ & $45(8 \cdot 8)$ \\
CWP category 0 & 1063 & $12 \cdot 1$ & $85(8 \cdot 0)$ \\
CWP category 1 & 3879 & $11 \cdot 3$ & $102(2 \cdot 6)$ \\
CWP category 2 & 500 & $11 \cdot 1$ & $62(12 \cdot 4)$ \\
CWP category 3 & 308 & $11 \cdot 3$ & $58(18 \cdot 8)$ \\
Pit pure men & 85 & 10.9 & $35(41 \cdot 2)$ \\
Non-pit pure men & 2112 & $11 \cdot 4$ & $85(4 \cdot 0)$ \\
All men & 2660 & $11 \cdot 2$ & $172(6 \cdot 5)$ \\
\hline
\end{tabular}

CWP $=$ Coalworkers' pneumoconiosis

(SD7) and $242 \mathrm{gh} / \mathrm{m}^{3}$ (SD 111) compared with 48 (SD $10)$ and $153 \mathrm{gh} / \mathrm{m}^{3}$ (SD 107) for the 4515 other men.

\section{QUALITY OF THE MATCHING}

The average difference in exposure to dust between cases and controls was $0 \cdot 3 \mathrm{gh} / \mathrm{m}^{3}$ (SE 0.5). This is a negligible quantity compared with the mean exposure to dust for all 4772 men $\left(157.7 \mathrm{gh} / \mathrm{m}^{3}\right)$ and the matching appears to be satisfactory. Nevertheless, cases at the six high rank collieries in south Wales had $1.8 \mathrm{gh} / \mathrm{m}^{3}$ less exposure than their matched controls (SE 0.9) and in regression analyses allowance was made for this difference between cases and controls in high rank collieries.

AGE, PHYSIQUE, SMOKING, TIME CONTRIBUTING TO EXPOSURE

The results in table 3 show that the matching process has caused the mean values of age and time contributing to dust exposure for controls to be closer to the corresponding values for cases than to those for all 4772 men. This reflects the positive correlations between these characteristics and dust exposure. Note, however, that there is no such effect for Quetelet's index.

On average, cases were older than their matched controls by 2.3 years (SE 0.5 ). They were also less heavy for their height $\left(1.5 \mathrm{~kg} / \mathrm{m}^{2}\right.$, SE 0.2$)$, a finding that held with small variation in each of the three groups of collieries. Table 3 provides no evidence that the development of PMF was associated with smoking; slightly more cases than controls were ex-smokers $(3.4 \%$, SE $2.6 \%)$ and rather fewer cases were nonsmokers $(3 \cdot 3 \%$, SE $2 \cdot 8 \%)$. Finally, cases had a greater number of hours contributing to dust exposure $(2500$ hours, SE 900), a finding especially pronounced in high rank collieries in south Wales $(4100$ hours, SE 1700). Stepwise conditional logistic modelling showed that age and Quetelet's index, considered jointly, were each strongly associated with the incidence of PMF (table 4). Furthermore, the fitted odds ratios differed only slightly from those obtained when each variable was fitted separately, suggesting that these factors influenced the incidence of PMF independently of each other. After allowing for age and physique, neither time contributing to dust exposure nor smoking habit had a statistically significant influence on the incidence of PMF.

\section{RESIDENCE TIME, COMPOSITION OF AIRBORNE}

DUST, PARTICLE SIZE

Among the environmental factors, the clearest casecontrol difference was in the residence time of dust in

Table 3 Mean values of listed characteristics, or percentage showing listed attributes, with associated standard errors of case-control differences*

\begin{tabular}{|c|c|c|c|c|c|c|}
\hline \multirow[b]{2}{*}{ Characteristic } & \multirow[b]{2}{*}{$\begin{array}{l}\text { Study group } \\
\text { mean (SD) } \\
(4772 \text { men) }\end{array}$} & & \multicolumn{4}{|l|}{ Colliery group } \\
\hline & & & $\begin{array}{l}\text { All collieries } \\
(245 \text { matched sets })\end{array}$ & $\begin{array}{l}\text { Low rank collieries } \\
\text { (122 matched sets) }\end{array}$ & $\begin{array}{l}\text { Medium rank } \\
\text { collieries } \\
(43 \text { matched sets })\end{array}$ & $\begin{array}{l}\text { High rank } \\
\text { collieries } \\
\text { / } 80 \text { matched sets }\end{array}$ \\
\hline Dust exposure (gh/m $)$ & $158(109)$ & Cases & 237 & 216 & 240 & 268 \\
\hline & & Difference (SE) & $-0.3(0.5)$ & $0.6(0.8)$ & $-0 \cdot 2(1 \cdot 2)$ & $-1 \cdot 8(0 \cdot 9)$ \\
\hline Rige (y) & $47 \cdot 8(9 \cdot 6)$ & Cases & $53 \cdot 8$ & $55 \cdot 3$ & $53 \cdot 5$ & $51 \cdot 7$ \\
\hline Q:1etelet's index $\left(\mathrm{kg} / \mathrm{m}^{2}\right)$ & $25.4(3.4)$ & $\begin{array}{l}\text { Cases } \\
\text { Cance ( }\end{array}$ & $\begin{array}{l}2 \cdot 3(0 \cdot 5) \\
23 \cdot 9\end{array}$ & $24 \cdot 1$ & $\begin{array}{l}2 \cdot \cdot 1(1 \cdot 0) \\
23 \cdot 9\end{array}$ & $23 \cdot 6$ \\
\hline & & Difference (SE) & $-1 \cdot 5(0 \cdot 2)$ & $-1 \cdot 3(0.3)$ & $-1.4(0.5)$ & $-1.8(0.4)$ \\
\hline Smokers (\%) (4749 men) & $72 \cdot 2$ & Cases & $72 \cdot 7$ & $74 \cdot 6$ & $79 \cdot 1$ & $66 \cdot 3$ \\
\hline Ex-smokers (\%) (4749 men) & $12 \cdot 7$ & $\begin{array}{l}\text { Dinterence (SE) } \\
\text { Cases }\end{array}$ & $\begin{array}{c}0.0(3 \\
13 \cdot 9\end{array}$ & $13.9\left(4^{\circ}\right.$ & $\begin{array}{l}3 \cdot 3(7 \cdot 6) \\
7 \cdot 0\end{array}$ & $\begin{array}{l}-4 \cdot 0(6 \cdot 5) \\
17 \cdot 5\end{array}$ \\
\hline & & Difference (SE) & $3 \cdot 4(2 \cdot 6)$ & $3 \cdot 2(3 \cdot 7)$ & $-1.9(4.6)$ & $6 \cdot 5(5 \cdot 2)$ \\
\hline $\begin{array}{l}\text { ivon-smokers }(\%) \\
\quad(4749 \text { men })\end{array}$ & $15 \cdot 1$ & Cases & 13.5 & 11.5 & $14 \cdot 0$ & $16 \cdot 3$ \\
\hline Time contributing to dust & $52.0(18 \cdot 6)$ & $\begin{array}{l}\text { Difference (SE) } \\
\text { Cases }\end{array}$ & $\begin{array}{l}-3 \cdot 3(2 \cdot 8) \\
62 \cdot 7\end{array}$ & $\begin{array}{l}-4 \cdot 6(3 \cdot 7) \\
64 \cdot 6\end{array}$ & $\begin{array}{l}-1 \cdot 3(7 \cdot 1) \\
61 \cdot 7\end{array}$ & $\begin{array}{l}-2 \cdot 5(5 \cdot 1) \\
60 \cdot 4\end{array}$ \\
\hline exposure (1000s of hours) & & Difference (SE) & $2 \cdot 5(0.9)$ & $1 \cdot 7(1 \cdot 1)$ & $1.9(2 \cdot 3)$ & $4 \cdot 1(1 \cdot 7)$ \\
\hline
\end{tabular}

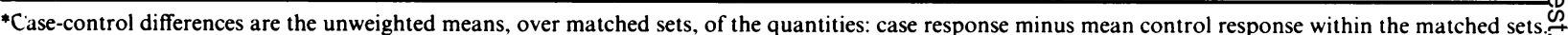
Standard errors are calculated directly from these within-set differences. 
Table 4 Natural exponents of estimated logistic regression coefficients (interpretable as odds ratios) together with corresponding $p$ values, for certain characteristics. (Variables listed in order of entering the regression equation)

\begin{tabular}{lll}
\hline Characteristic & Odds ratio & $p$ \\
\hline Quetelet's index $\left(\mathrm{kg} / \mathrm{m}^{2}\right)$ & Per decrease of $3 \mathrm{~kg} / \mathrm{m}^{2}: 1.60$ & $<0.001$ \\
Age $(\mathrm{y})$ & Per increase of 5 years: 1.38 & $<0.001$ \\
\hline
\end{tabular}

the lungs $(0 \cdot 58$ years, SE $0 \cdot 13$, table 5$)$. Other characteristics showing signs of association with the incidence of PMF were the average concentrations of quartz and kaolin plus mica in mixed respirable dust and the average particle size of dust. Cases were exposed to $0.008 \mathrm{mg} / \mathrm{m}^{3}$ less quartz concentration than their matched controls (SE 0.003), the difference being greatest and most statistically significant in high rank collieries $\left(0.012 \mathrm{mg} / \mathrm{m}^{3}, \mathrm{SE} 0.004\right)$ but somewhat less both in magnitude and significance in other collieries. A similar pattern was evident for kaolin plus mica concentration. The average particle size index of the dust to which cases had been exposed exceeded that of controls by 0.006 units (SE 0.002), indicating that cases had been exposed to finer dusts. This effect was most pronounced in medium and high rank collieries but statistical significance was suggested only in the latter, where the airborne dust is relatively coarse. Table 6 shows the results of stepwise conditional logistic regression analysis for this group of factors. After allowing for age and physique, residence time was the characteristic most clearly associated with the incidence of PMF; an increment of two years increased the odds of an attack of PMF over the study period by an estimated $31 \%(\mathrm{p}=0.02)$. There was also a suggestion that cumulative exposure to the quartz component of dust was negatively associated with the incidence of PMF, allowance being made for age, physique, and residence time. (The direction of the association is consistent with the negative signs of case-control differences in concentrations of these components shown in table 5.) After adjusting for residence time and exposure to quartz, the effects of the kaolin plus mica component of dust, or of particle size, were not found to be statistically significant. Furthermore, there was no evidence of differences between colliery groups in the magnitudes of environmental effects on the incidence of PMF.

Case-control differences in environmental characteristics were also examined for pit pure men only (76 matched sets). The general pattern of results was similar, the clearest case-control difference being again in the residence time of dust in the lung $(0.88$ years, SE $0 \cdot 28$ ). Pit pure cases at high rank collieries had been exposed to lower average concentrations of quartz $\left(0.013 \mathrm{mg} / \mathrm{m}^{3}, \mathrm{SE} 0.007\right)$ and kaolin plus mica $(0.069$ $\mathrm{mg} / \mathrm{m}^{3}$, SE 0.043 ) than their matched controls, but differences for other colliery groups were less than their standard errors. Similarly, only cases at high rank collieries were found to have been exposed to finer dusts (0.009 units, SE 0.004). After allowing for age and physique in a regression analysis, none of the effects of environmental factors was found to be significant.

\section{CATEGORY OF SIMPLE PNEUMOCONIOSIS, LUNG}

FUNCTION, AND RESPIRATORY SYMPTOMS

Table 1 shows that men who developed PMF had, on average, higher categories of simple pneumoconiosis at the third survey than their matched controls $(0 \cdot 60$ steps on the four point scale, SE 0.07). Differences of roughly this order were observed in each of the three groups of collieries. Conditional logistic analysis established the statistical significance of these effects

Table 5 Mean values of listed characteristics, or percentage showing listed attributes, with associated standard errors of case-control differences*

\begin{tabular}{|c|c|c|c|c|c|c|}
\hline \multirow[b]{2}{*}{ Characteristic } & \multirow[b]{2}{*}{$\begin{array}{l}\text { Study group } \\
\text { mean (SD) } \\
(4772 \text { men) }\end{array}$} & & \multicolumn{4}{|l|}{ Colliery group } \\
\hline & & & $\begin{array}{l}\text { All collieries } \\
(245 \text { matched sets })\end{array}$ & $\begin{array}{l}\text { Low rank collieries } \\
(122 \text { matched sets })\end{array}$ & $\begin{array}{l}\text { Medium rank } \\
\text { collieries } \\
(43 \text { matched sets) }\end{array}$ & $\begin{array}{l}\text { High rank } \\
\text { collieries } \\
\text { ( } 80 \text { matched sets }\end{array}$ \\
\hline Quartz exposure $\left(\mathrm{gh} / \mathrm{m}^{3}\right)$ & $6 \cdot 9(5 \cdot 1)$ & $\begin{array}{l}\text { Cases } \\
\text { Difference (SE) }\end{array}$ & $\begin{array}{l}10 \cdot 1 \\
-0.06 \quad(0 \cdot 10)\end{array}$ & $\begin{array}{l}11.0 \\
-0.07 \quad(0.11)\end{array}$ & $\begin{array}{l}12.0 \\
-0.07 \quad(0.41)\end{array}$ & $\begin{array}{cc} & 7.6 \\
- & 0.04 \quad(0.15)\end{array}$ \\
\hline $\begin{array}{l}\text { Kaolin plus mica exposure } \\
\left(\mathrm{gh} / \mathrm{m}^{3}\right)\end{array}$ & $29 \cdot 7(23 \cdot 8)$ & $\begin{array}{l}\text { Cases } \\
\text { Difference (SE) }\end{array}$ & $\begin{array}{ll}42.2 & \\
-0.29 & (0.37)\end{array}$ & $\begin{array}{l}47.2 \\
-0.34 \quad(0.46)\end{array}$ & $\begin{array}{l}32.4 \\
-1.22 \quad(1.00)\end{array}$ & $\begin{array}{cc}40.0 & \\
0.29 & (0.73)\end{array}$ \\
\hline $\begin{array}{l}\text { Quartz concentration } \\
\left(\mathrm{mg} / \mathrm{m}^{3}\right)\end{array}$ & $0.133(0.085)$ & $\begin{array}{l}\text { Cases } \\
\text { Difference (SE) }\end{array}$ & $\begin{aligned} & 0 \cdot 160 \\
- & 0.008(0.003)\end{aligned}$ & $\begin{aligned} 0.170 \\
-0.006(0.004)\end{aligned}$ & $\begin{array}{r}0.194 \\
-0.005(0.008)\end{array}$ & $\begin{array}{r}0.125 \\
-0.012(0.004\end{array}$ \\
\hline $\begin{array}{l}\text { Kaolin plus mica } \\
\text { concentration }\left(\mathrm{mg} / \mathrm{m}^{3}\right)\end{array}$ & $0.57(0.40)$ & $\begin{array}{l}\text { Cases } \\
\text { Difference (SE) }\end{array}$ & $\begin{array}{l}0.67 \\
-0.036(0.012)\end{array}$ & $\begin{aligned} & 0.73 \\
- & 0.028(0.016)\end{aligned}$ & $\begin{array}{l}0.53 \\
-0.032(0.025)\end{array}$ & $\begin{array}{l}0.67 \\
-0.051(0.022)\end{array}$ \\
\hline $\begin{array}{l}\text { Particle size } \\
\left(\mu^{\prime}\right)\end{array}$ & $0.623(0.156)$ & $\begin{array}{l}\text { Cases } \\
\text { Difference (SE) }\end{array}$ & $\begin{array}{l}0.562 \\
0.006(0.002)\end{array}$ & $\begin{array}{l}0.627 \\
0.004(0.003)\end{array}$ & $\begin{array}{l}0.571 \\
0.007(0.006)\end{array}$ & $\begin{array}{l}0.457 \\
0.007(0.003)\end{array}$ \\
\hline Residence time (y) & $12 \cdot 3(3 \cdot 0)$ & $\begin{array}{l}\text { Cases } \\
\text { Difference (SE) }\end{array}$ & $\begin{array}{cc}14 \cdot 1 & \\
0.58 & (0 \cdot 13)\end{array}$ & $\begin{array}{c}14.0 \\
0.43 \quad(0 \cdot 15)\end{array}$ & $\begin{array}{cl}14 \cdot 1 & \\
0.65 & (0.40)\end{array}$ & $\begin{array}{cc}14.4 & \\
0.77 & (0.28)\end{array}$ \\
\hline
\end{tabular}

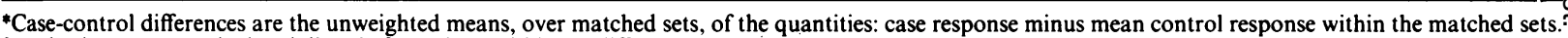
Standard errors are calculated directly from these within-set differences. 
Table 6 Natural exponents of estimated logistic regression coefficients (interpretable as odds ratios) together with corresponding $p$ values, for certain environmental characteristics entered in a stepwise procedure, allowing for the effects of age and Quetelet's index (other characteristics listed in order of entering the regression equation)

\begin{tabular}{llc}
\hline Characteristic & Odds ratio & $p$ \\
\hline $\begin{array}{l}\text { Age }(\mathrm{y}) \\
\text { Quetelet's index }\end{array}$ & Per increase of 5 years: 1.29 & $<0.001$ \\
$\left(\mathrm{~kg} / \mathrm{m}^{2}\right)$ & Per decrease of $3 \mathrm{~kg} / \mathrm{m}^{2}: 1.61$ & $<0.001$ \\
$\begin{array}{l}\text { Residence time }(\mathrm{y}) \\
\text { Quartz exposure } \\
\left(\mathrm{gh} / \mathrm{m}^{3}\right)\end{array}$ & Per increase of $2 \mathrm{years:} 1.31$ & 0.02 \\
\hline
\end{tabular}

(table 7). Note that the odds ratio parameters in the table are multiplicative; the risk of men with category 3 simple pneumoconiosis developing PMF is about $14 \cdot 1$ times the risk of men with category 0 developing the disease.

Average differences between 245 cases and their matched controls in the two lung function measures $\mathrm{FEV}_{1}$ and FVC were each more than twice their standard errors (table 1). There was no indication, however, of a significant difference in the ratio of FEV , to FVC. In high rank collieries differences in FEV, were smaller than those for men in the other two colliery groups but FVC differences were constant across the three groups of collieries. After allowing for dust exposure in high rank collieries and for age, height, and weight, by conditional logistic regression methods, the effects of FEV 1 and FVC were not statistically significant.

On average, all nine respiratory symptoms were more prevalent among cases than controls at the third survey (table 1). Differences were only found at collieries where low and medium rank coal was mined; in the high rank collieries of south Wales symptoms occurred with equal frequency in cases and controls. Conditional logistic regression analysis carried out for each symptom separately, adjusting for age and physique, showed that for "morning cough," "day

Table 7 Natural exponents of estimated logistic regression coefficients (interpretable as odds ratios) together with corresponding $p$ values, of age, Quetelet's index, and variables indicating the presence of CWSP, all considered jointly

\begin{tabular}{lll}
\hline Characteristic & Odds ratio & $p$ \\
\hline $\begin{array}{l}\text { Age }(y) \\
\text { Quetelet's index } \\
\left(\mathbf{k g} / \mathrm{m}^{2}\right)\end{array}$ & Per increase of 5 years: 1.40 & $<0.001$ \\
$\begin{array}{l}\text { CWSP category 1 } \\
\text { or more }\end{array}$ & Per decrease of $3 \mathrm{~kg} / \mathrm{m}^{2}: 1.63$ & $<0.001$ \\
$\begin{array}{l}\text { CWSP category 2 } \\
\text { or more }\end{array}$ & Relative to category 0: 3.10 & $<0.001$ \\
CWSP category 3 & $\begin{array}{l}\text { Relative to category 1: } 1.88 \\
\text { Relative to category 2: } 2.42\end{array}$ & $\begin{array}{l}0.02 \\
0.02\end{array}$ \\
\hline
\end{tabular}

CWSP $=$ Coalworkers' simple pneumoconiosis cough," "breathlessness," "wheeze," and "respiratory symptoms," there was evidence of real differences between high rank collieries and low and medium rank collieries in the magnitude of case-control differences (maximum $\mathrm{p}$ value 0.06). For these indicators, odds ratio parameters in low and mid-rank collieries varied from $1.65(p=0.01)$ for morning cough to 2.45 (p < 0.001 ) for breathlessness. Of the other four symptoms, both morning phlegm and history of recent chest illness were significantly associated over all colliery groups with the incidence of PMF (maximum $p$ value 0.03 ). A stepwise analysis, carried out for low and medium rank collieries only, established that breathlessness was the symptom most strongly associated with the development of PMF (odds ratio 2.39, p < 0.001 ), allowance being made for the effects of age and physique. After adjustment for it, no other symptoms indicator reached statistical significance.

\section{Discussion}

The presence or absence of PMF at the follow up survey in this study was decided purely on the basis of the self trained panel's identification of large shadows in the follow up survey films. The possibility that such appearances might be due to non-occupational disease, thus giving rise to false positive classifications, has been examined by Maclaren and Soutar, who concluded that the panel's readings were not seriously biased in this way. ${ }^{3}$ In any case there is no reason to suppose that mistakenly identified cases of PMF would be other than randomly distributed with respect to covariates. This would imply that, on average, no bias would be introduced into relative risk estimates, though the study's power to identify real effects would be affected adversely.

\section{AGE AND SIMPLE PNEUMOCONIOSIS}

Among the factors whose possible influence on PMF was considered in this study were two-namely, age and prior category of CWSP - whose effects have been studied and quantified on numerous occasions, ${ }^{4-7}$ and most recently by Hurley et al. ${ }^{1}$ These authors' findings have been confirmed by the results of the present study: older men, and men with higher starting categories of CWSP, were more likely to develop PMF after allowing for the effects of differing exposures to dust.

Comparison of the magnitudes of the effects of these factors with corresponding estimates of Hurley $e t a l,{ }^{1}$ the largest study so far published of PMF incidence rates, is not straightforward because of differences in study design and methodology. (For example, the present study group included a large proportion $(56 \%)$ of men who had left the mining industry by the time of follow up, whereas only working miners were 
studied by Hurley et al '; the two studies referred to different calendar periods-namely $1963-80$ for the present study and 1953-77 for Hurley et al ' ; reported incidence rates were for periods of 11 years (present study) and five years (Hurley et al ${ }^{\prime}$ ); the present study population was constrained to include men who had worked in the coal industry for at least 10 years and had not developed PMF during that time-in effect, a "survivor" population.) Nevertheless, comparison is to some extent facilitated by regarding the present estimated increase in risk of $38 \%$ per five years of age over an 11 year period as an average of separate relative risks for two consecutive periods of five and six years. Assuming constancy of the relative risk over the 11 year period, the present estimate of 1.38 is thus seen to be slightly larger than the estimate of 1.23 reported by Hurley et al ${ }^{1}$ (table 5 of that paper). Calculation of an approximate $95 \%$ confidence interval is also possible from table 5-the resulting range of $1 \cdot 13-1 \cdot 34$ overlaps the corresponding interval of 1.21-1.57 estimated from present data, showing that the two risk estimates do not differ significantly.

A bigger difference between the two studies is apparent on estimated relative risks of PMF between groups defined by category of CWSP. The specific example given by Hurley et al (table 6 of that paper) suggests an increase in risk between CWSP categories 0 and 1 of approximately $9,{ }^{\prime}$ whereas the corresponding estimate from the present study (table 7) is $3 \cdot 1$. Results of Hurley and Maclaren suggest that the discrepancy may be partly due to the large proportion of ex-miners in the present study group. ${ }^{2}$ In an analysis of the same group of $\mathbf{4 7 7 2}$ men these authors found that the ratio of risks of an attack of PMF in current miners with prior CWSP category 1 relative to those with category 0 was $6 \cdot 1$; the corresponding relative risk for ex-miners was 1.5 . The present estimate of 3.1 would therefore represent an average of these two results and this figure clearly depends on the proportion of ex-miners. In view of this lack of homogeneity of risk, it is impossible to give a single figure summary of the relative risk of PMF between groups of men with prior CWSP categories 0 and 1 without further qualification.

\section{PHYSIQUE}

The results with respect to Quetelet's index of physique are particularly interesting. Craw, studying iron ore miners who showed radiological signs, found that the prevalence of massive fibrosis was clearly higher among men with asthenic build than in other groups. ${ }^{24} \mathrm{~A}$ similar trend was noted at about the same time in a cross sectional survey of Welsh coalminers carried out by the Medical Research Council. When reporting the latter results, Oldham pointed to the need for a longitudinal study so that cause and effect patterns between PMF and body type could be $\bar{\alpha}$ disentangled. ${ }^{25}$ Early results from such a longitudinal $\frac{}{z}$ study did suggest a relation of physique to subsequent $\stackrel{\otimes}{\circ}$ attacks of $\mathrm{PMF}^{\mathrm{s}}$ but observations over a longer follow up period failed to confirm an association. ${ }^{4}$ More $\overrightarrow{\vec{D}}$ recent analysis by Cochrane of these and other data, $\overline{0}$ while not confirming the influence of physique as $\overline{0}$ represented by Quetelet's index, suggested that poss- $\overline{\bar{\sigma}}$ ible associations with weight should be considered $\widetilde{\Phi}$ (personal communications, 1979 and 1983), and so encouraged us to investigate the role of physique in the ${ }^{\infty}$ present study. The results reported now show a strong. $\vec{\circ}$ and consistent association between Quetelet's index, $\vec{\overrightarrow{ }}$ measured at initial survey, and attacks of PMF during $\stackrel{\omega}{\omega}$ the subsequent approximately 11 year period. The $O$ association is evident among men surveyed in collieries $\frac{\mathbb{D}}{3}$ producing high, medium, and low rank coals. Differences between cases and controls were highly significant statistically, even when age and category of $i$ simple pneumoconiosis were also taken into account (table 7).

It is interesting to speculate on possible reasons for the observed association. One simple explanationes might be that a taller man working in the confinedo space of a coalface may be at a disadvantage compared $\overrightarrow{\mathbb{D}}$ with his shorter colleagues. Because he is forced too work less efficiently, a greater dose of dust may be delivered to the lung. Another possibility is thatco because his "dead space" is greater, the taller mirero may require a greater volume per breath in order maintain alveolar ventilation (assuming equal brea:ing frequency). This would not, however, necessarily increase the amount of air (and therefore dust par-o ticles) carried to the alveolar regions, whereas underio the first hypothesis it is at least plausible that the dust dose might increase.

Whatever the underlying mechanism, the finding seems to present, at least in theory, the possibility of distinguishing men who may be at particular risk of developing the disease. Although we have not yet? investigated this problem in detail, the results of a 3 limited statistical analysis suggested that such dis- $\frac{0}{3}$ crimination would not be practical. ${ }^{26}$

\section{ENVIRONMENTAL FACTORS}

Of the different characterisations of lifetime exposure to dust, the one which showed the strongest associa- -7 tion with the incidence of PMF was residence time. After adjusting for differences in age and physique, its $N$ effect (an approximate $31 \%$ increase in risk for each two years increase in time, see table 6) remained 0 statistically significant $(p=0.02)$. Admittedly, thew measurement of residence time in the present study was crude. Furthermore, the possibility exists thato residence time was acting as a substitute variable for dust exposure in conditions where exposures before? + 
the first PFR survey were underestimated. A more refined definition of the characteristic was used in a study of 4500 German miners over periods of up to 18 years by Reisner and Breuer, who showed that risks of developing CWSP increased with increasing residence time, after allowing for the effects of dust exposure. ${ }^{27}$ Research in Britain based on 2600 miners who had worked on average 35 years in the industry also showed that, after adjustment for the effects of exposure, the risks of developing category 2 or more CWSP increased with the period over which the exposures were accumulated. ${ }^{14} \mathrm{We}$ therefore think that the findings of the present study may point to a real effect of residence time on the risks of PMF, although further work to confirm the association is necessary, using if possible a more sensitive index.

Results in table 5 suggest that of the compositional variables, those most clearly associated with the incidence of PMF were the concentrations of quartz and of kaolin plus mica, and that these associations mainly resulted from comparatively large case-control differences in high rank collieries. After allowing for the effects of age, physique, and residence time, however, it was cumulative exposure to quartz rather than its average concentration that was found to have a negative association with the incidence of $\operatorname{PMF}(p=$ 0.06 ). The naive interpretation, that exposure to quartz protects against PMF, is not plausible biologically and is inconsistent with other findings that have established a positive association between rapid progression of simple pneumoconiosis and exposure to relatively high levels of quartz. ${ }^{28} 29$ In two previous investigations where an apparent negative association between exposure to quartz and radiological abnormality has been reported the authors have emphasised the inappropriateness of attributing a protective influence to quartz dust. Thus Walton et al reported that the probability of progression of CWSP in a group of 3154 faceworkers (all surveyed as part of the PFR) over a 10 year period was inversely related to the percentage quartz content of the dust. ${ }^{30}$ Those authors pointed out that since there is a negative correlation between coal rank and mineral content, "an alternative interpretation - that is, of the finding - might be that coals of lower rank are less harmful." (Such an interpretation could equally well apply in the present study.) Reisner et al also drew attention to the apparently decreasing risk of pneumoconiosis in $18000 \mathrm{Ruhr}$ coalfield miners with increasing percentage quartz in respirable dust and emphasised the discrepancy between such findings and the known toxic effects of quartz dust. ${ }^{31}$

In general, results from the present study do not greatly clarify our understanding of the role of noncoal minerals in the development of PMF. One possible reason is that in the full study group of $\mathbf{4 7 7 2}$ men the compositional data were closely associated with dust exposure, colliery, and, to a lesser extent, pit purity. Consequently, much of the natural variability of the compositional characteristics was eliminated by the matching process, a reduction in variability that may be simply quantified by partitioning the variance between and within matched sets. Thus matching removed $86.7 \%$ and $95.4 \%$ of the total variation in quartz concentration and quartz exposure, respectively, for these men. Such reductions are severe when compared with the corresponding figures for Quetelet's index $(25 \cdot 5 \%)$ or age $(55 \cdot 9 \%)$.

Particle size was of interest because the collieries where the attack rates of PMF were highest were also those with relatively coarse dust and because mechanisms are plausible whereby the size and shape of particles affect their site of deposition and subsequent clearance after inhalation. In the event we studied only an average index of projected diameter, determined by light microscope; corresponding data on other parameters-for example, aerodynamic diameter, volume, and shape-were unavailable. Variation in particle size measurements was also restricted severely by the strict matching criteria adopted and the magnitudes of the case-control differences were in general small. An association with incidence of PMF, however, was found, most clearly so in south Wales (table 5). Contrary to expectation it suggested that, within a colliery, slightly higher risks were experienced by men exposed to finer dusts. It may be that matching for colliery and previous exposure to dust had successfully eliminated the confounding effects of these and other related characteristics, leading to a correct but unexpected result in the case-control study. On the other hand, the case-control finding may be due to selection effects, as follows. Workers at the coalface are generally exposed to coarser airborne dust than are miners working elsewhere underground and the association found may reflect movements of men in their coalmining jobs, perhaps in response to the presence of simple pneumoconiosis, rather than an effect of the dust itself.

RESPIRATORY SYMPTOMS, LUNG FUNCTION, AND SMOKING

Smoking has not been shown to be related to the incidence of simple pneumoconiosis ${ }^{32}$ and, on the evidence of this study, is unrelated to the occurrence of PMF. The study also provided no evidence that level of lung function at the third survey was related to the chances of subsequently developing PMF, though it has long been established that the lung function of men with PMF is worse than that of others of similar age. ${ }^{17}$

Several aspects of the results on respiratory symptoms (table 1) are interesting, however. One is their consistency: all nine case-control differences in 
prevalence, with only one exception, were greater than twice their standard errors. A second is the sharp contrast between results from the high rank collieries of south Wales and those from elsewhere. Prevalences among controls at high rank collieries were about the same as among cases generally. This pattern, especially when considered in conjunction with the results on quartz and kaolin plus mica concentrations and on particle size, enhances the impression of the distinctive nature of PMF in high rank collieries. ${ }^{33}$ Finally, analyses at low and medium rank collieries highlighted breathlessness as the symptom most strongly associated with PMF, with more than a twofold increase in relative risk, highly significant statistically, after matching and adjustment for age and exposure. We have been unable to find an obvious explanation of this association; one possibility is that men who complain of breathlessness may, for a given dust exposure, inhale and retain a greater dose of dust because of differences in breathing pattern.

\section{FURTHER WORK}

The present study, while confirming the well known associations of age and attained category of CWSP with the incidence of PMF, has for the first time established clearly that miners of asthenic build are more likely than others to experience an attack of PMF. It has also provided strongly suggestive evidence of an association with the residence time of dust in the lung and shown that breathlessness is a predisposing factor (but not at high rank collieries). Smoking habit and lung function level were not found to be associated with the incidence of PMF. The role of dust composition and of particle size remains unclear.

It is now possible for physicians experienced in the classification of pneumoconiosis to distinguish the radiological appearances of PMF sufficiently reliably so that factors influencing the occurrence of PMF of various types may be studied epidemiologically. ${ }^{34} 35$ With colleagues, we are currently engaged in such a study, which we hope will answer some of the unresolved questions from the present work.

\section{Appendix}

\section{STUDY DESIGN}

A case-control approach to the statistical analysis was used because it provided an efficient means of allowing for the effects of cumulative exposure to mixed dust on the incidence of PMF which have been clearly shown. Factors other than dust exposure, however, were also known to be associated with attack rates of PMFmost notably, prior category of CWSP, age, and colliery of employment. Whether or not to make initial adjustment for the effects of colliery by matching presented a difficult problem. There are pronounced colliery related variations in the incidence of PMF and $\bar{F}$ values of environmental variables are also colliery related. Indeed, much of the natural variation in $\mathrm{D}$

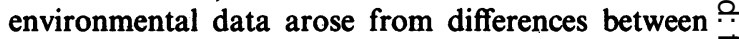
collieries rather than from differences between $\overrightarrow{\vec{F}}$ individuals at the same pits. Carbon content of the coal is an extreme example. Men at any one colliery $\frac{C}{0}$ work with coal for which we have a single value of per $\overline{\bar{c}}$ cent carbon, and so the role of carbon content could $\vec{\nabla}$ not be investigated if the analyses were restricted to 2 comparisons between men at the same pits. On the कs other hand, any findings of associations between other $\overrightarrow{0}$ environmental characteristics and incidence of PMF $\vec{A}$ would be stronger, and more easy to interpret, if other $\vec{\omega}$ colliery related differences had already been taken into $\bar{O}$ account. Ideally, we would have studied the data both $\frac{\mathbb{D}}{3}$ ways, with and without matching for colliery differences. In the event we opted to make our main compar- of isons between men surveyed at the same pits.

Matching, however, was not used to adjust for either age or simple pneumoconiosis category at the $ᄋ$ third survey. Both these characteristics are known to be related to subsequent incidence of PMF and both $\infty$ are also related to many of the possibly influential $\mathbb{D}$ characteristics being examined. But the presence of $\mathbb{D}$ CWSP may itself be a response to aspects of exposure $\frac{3}{0}$ under investigation; by matching for CWSP category, $\stackrel{\Phi}{工}$ one runs the risk of diluting the effects of these other $\vec{\theta}$ causal factors. And the extent to which an association of age with PMF really reflects earlier exposures aspects of the coalmining environment is unknown. $\bar{q}$ therefore seemed wise to retain the option of examining environmental factors both with and without adjustment for age.

Finally, the available measures of environmental characteristics are, in general, more reliable for pit pure men; and so, though possible associations between pit purity and occurrences of PMF were not explored in any detail, we decided also to compare like with like in terms of quality of data and so take account of pit purity at an early stage.

We gratefully acknowledge the help of many colleagues at the Institute of Occupational Medicine and also the support of the European Coal and Steel Community and the National Coal Board in Britain.

\section{References}

1 Hurley JF, Alexander WP, Hazledine DJ, Jacobsen M, Maclaren WM. Exposure to respirable coalmine dust and incidence of progressive massive fibrosis. Br J Ind Med 1987;44:661-72.

2 Hurley JF, Maclaren WM. Factors influencing the occurrence of $\omega$ progressive massive fibrosis (PMF) in miners and ex-miners. In: Dodgson J, McCallum RI, Bailey MR, Fisher DR, eds. Inhaled particles VI. Oxford: Pergamon Press, 1988:575-83.

3 Maclaren WM, Soutar CA. Progressive massive fibrosis and 
simple pneumoconiosis in ex-miners. Br J Ind Med 1985;42: 734-40.

4 Cochrane AL. The attack rate of progressive massive fibrosis. $\mathrm{Br} \mathrm{J}$ Ind Med 1962;19:52-64.

5 Cochrane AL, Miall WE. Factors influencing the radiological attack rate of progressive massive fibrosis. $\mathrm{Br}$ Med $\mathrm{J}$ 1956; i:1193-9.

6 Shennan DH, Washington JS, Thomas DJ, Dick JA, Kaplan YS, Bennett JG. Factors predisposing to the development of progressive massive fibrosis in coalminers. $\mathrm{Br} \mathrm{J}$ Ind $\mathrm{Med}$ 1981;38:321-6.

7 McLintock JS, Rae S, Jacobsen M. The attack rate of progressive massive fibrosis in British coalminers. In: Walton WH, ed. Inhaled particles III. Vol 2. Old Woking: Unwin Bros, 1971: 933-52

8 Jacobsen M, Rae S, Walton WH, Rogan JM. The relation between pneumoconiosis and dust-exposure in British coal mines. In: Walton WH, ed. Inhaled particles III. Vol 2. Old Woking: Unwin Bros, 1971:903-19.

9 Soutar CA, Maclaren WM, Annis R, Melville AWT. Quantitative relations between exposure to respirable coalmine dust and coalworkers' simple pneumoconiosis in men who have worked as miners but have left the coal industry. $\mathrm{Br} J$ Ind Med 1986;43:29-36.

10 International Labour Organisation. ILO U/C international classification of radiographs of the pneumoconioses 1971 . Geneva: International Labour Office, 1972. (Occupational safety and health series No 22.)

11 Copland L, Burns J, Jacobsen M. Classification of chest radiographs for epidemiological purposes by people not experienced in the radiology of pneumoconiosis. $\mathrm{Br} \mathrm{J}$ Ind $\mathrm{Med}$ 1981;38:254-61.

12 Fay JWJ, Ashford JR. The study of observer variation in the radiological classification of pneumoconiosis. $\mathrm{Br} J$ Ind Med 1960;17:279-92.

13 International Labour Organisation. Meeting of experts on the international classification of radiographs of the pneumoconioses. Geneva: International Labour Office, 1959. (Occupational safety and health series No 9.)

14 Hurley JF, Burns J, Copland L, Dodgson J, Jacobsen M. Coalworkers' simple pneumoconiosis and exposure to dust at 10 British coalmines. Br J Ind Med 1982;39:120-7.

15 Dodgson J, Cowie AJ, Paris I, Whittaker W. A study of the importance of dust composition in relation to pneumoconiosis in coalminers. Edinburgh: Institute of Occupational Medicine, 1977. (IOM report No TM $/ 77 / 8$.)

16 Fay JWJ, Ashford JR. Size distribution of airborne dust samples from British coalmines. British Journal of Applied Physics 1960;11:1-13.

17 Rogan JM, Ashford JR, Chapman PJ, Duffield DP, Fay JWJ, Rae S. Pneumoconiosis and respiratory symptoms in miners at eight collieries. Br Med J 1961;i:1337-42.

18 Hurley JF, Maciaren WM, Alexander WP, et al. Factors influencing the occurrence of progressive massive fibrosis in British coalminers. Edinburgh: Institute of Occupational Medicine, 1984. (IOM report No TM $/ 84 / 2$.)

19 Khosla T, Lowe CR. Indices of obesity derived from body weight and height. Br J Prev Soc Med 1967;21:122-8.

20 Van Krevelen DIV, Schuyer J. Coal science. Aspects of coal constitution. Amsterdam: Elsevier, 1957.

21 Breslow NE, Day NE. Statistical methods in cancer research. Vol 1. The analysis of case-control studies. Lyon: International Agency for Research on Cancer, 1980.

22 Thomas DC. Program "risk" release 4-February 1980 user's manual. Montreal: McGill University, 1980.

23 Cox DR, Hinkley DV. Theoretical statistics. London: Chapman and Hall, 1974.

24 Craw J. A note on somatotyping in relation to certain chest conditions. Transactions of the Association of Industrial Medical Officers 1953;3:215-8.

25 Oldham PD. Discussion of paper by Dr Craw. Transactions of the Association of Industrial Medical Officers 1953;3:218-9.

26 Maclaren WM. Using discriminant analysis to predict attacks of complicated pneumoconiosis in coalworkers. The Statistician 1985;34:197-208.

27 Reisner MTR, Breuer H. Epidemiologische Untersuchungen uber Pneumokoniose und Staubexposition. Essen: BergbauForschung GMBH, 1982. (Final report on CEC Project No 6253-32/1/055.)

28 Jacobsen M, Maclaren WM. Unusual pulmonary observations and exposure to coalmine dust: a case-control study. In: Walton WH, ed. Inhaled particles V. Oxford: Pergamon Press, 1982 753-65.

29 Seaton A, Dick JA, Dodgson J, Jacobsen M. Quartz and pneumoconiosis in coal miners. Lancet 1981:ii:1272-5.

30 Walton WH, Dodgson J, Hadden GG, Jacobsen M. The effect of quartz and other non-coal dusts in coalworkers' pneumoconiosis. In: Walton WH, ed. Inhaled particles IV. Vol 2. Oxford: Pergamon Press, 1977:669-90.

31 Reisner MTR, Bruch J, Hilscher W, et al. Specific harmfulness of respirable dusts from West German coal mines. VI: Comparison of experimental and epidemiological results. In: Walton WH, ed. Inhaled particles $V$. Oxford: Pergamon Press, 1982: 527-39.

32 Jacobsen M, Burns J, Attfield MD. Smoking and coalworkers simple pneumoconiosis. In: Walton WH, ed. Inhaled particles $I V$. Vol 2. Oxford: Pergamon Press, 1977:759-72.

33 Davis JMG, Chapman J, Collings P, et al. Variations in the histological patterns of the lesions of coal workers pneumoconiosis in Britain and their relationship to lung dust content. Am Rev Respir Dis 1983;128:118-24.

34 Soutar CA, Collins HPR. Classification of progressive massive fibrosis of coalminers by type of radiographic appearance. $\mathrm{Br} J$ Ind Med 1984:41:334-9.

35 Collins HPR, Soutar CA. Reproducibility of a radiographic classification of progressive massive fibrosis. In: Dodgson $J$. McCallum RI, Bailey MR, Fisher DR, eds. Inhaled particles VI. Oxford: Pergamon Press, 1983:567-73. 